\title{
Absolute Cardiovascular Disease Risk and Shared Decision Making in Primary Care: A Randomized Controlled Trial
}

\author{
Tanja Krones, $M D^{1,2}$ \\ Heidemarie Keller, $P b D^{3}$ \\ Andreas Sönnichsen, $M D^{4}$ \\ Eva-Maria Sadowski, $M D^{3}$ \\ Erika Baum, MD ${ }^{3}$ \\ Karl Wegscheider, $\mathrm{PbD}^{5}$ \\ Justine Rochon, $\mathrm{MSc}^{6}$ \\ Norbert Donner-Banzhoff, $M D^{3}$ \\ ${ }^{1}$ Department of General Practice/Family \\ Medicine, Phillips-University Marburg, \\ Marburg, Germany \\ ${ }^{2}$ Department of Bioethics/Clinical Ethics, \\ Phillips-University Marburg, Marburg, \\ Germany \\ ${ }^{3}$ Department of Family Medicine, Phillips- \\ University Marburg, Marburg, Germany \\ ${ }^{4}$ Institute of General Practice, Family Medi- \\ cine and Prevention, Paracelsus Medical \\ University, Salzburg, Austria \\ ${ }^{5}$ Department of Medical Biometry and Epi- \\ demiology, University of Hamburg, Ham- \\ burg, Germany \\ ${ }^{6}$ Statistician Center for Clinical Studies, \\ University Hospital, Regensburg, Germany
}

Conflicts of interest: none reported

\section{CORRESPONDING AUTHOR}

Tanja Krones, MD

Klinikum der Philipps-Universität Marburg

Baldingerstrasse

35033 Marburg

krones@med.uni-marburg.de

\begin{abstract}
PURPOSE We wanted to determine the effect of promoting the effective communication of absolute cardiovascular disease (CVD) risk and shared decision making through disseminating a simple decision aid for use in family practice consultations.

METHODS The study was based on a pragmatic, cluster randomized controlled trial (phase III) with continuing medical education (CME) groups of family physicians as the unit of randomization. In the intervention arm, 44 physicians (7 CME groups) consecutively recruited 550 patients in whom cholesterol levels were measured. Forty-seven physicians in the control arm (7 CME groups) similarly included 582 patients. Four hundred sixty patients (83.6\%) of the intervention arm and 466 patients (80.1\%) of the control arm were seen at follow-up. Physicians attended 2 interactive CME sessions and received a booklet, a paper-based risk calculator, and individual summary sheets for each patient. Control physicians attended 1 CME-session on an alternative topic. Main outcome measures were patient satisfaction and participation after the index consultation, change in CVD risk status, and decisional regret at 6 months' follow-up.
\end{abstract}

RESULTS Intervention patients were significantly more satisfied with process and result (Patient Participation Scale, difference 0.80, $P<.001)$. Decisional regret was significantly lower at follow-up (difference $3.39, P=.02$ ). CVD risk decreased in both groups without a significant difference between study arms.

CONCLUSION A simple transactional decision aid based on calculating absolute individual CVD risk and promoting shared decision making in CVD prevention can be disseminated through CME groups and may lead to higher patient satisfaction and involvement and less decisional regret, without negatively affecting global CVD risk.

Ann Fam Med 2008;6:218-227. DOI: 10.1370/afm.854.

\section{INTRODUCTION}

Tnolving patients in decisions about their own health care is considered important from an ethical, ${ }^{1,2}$ clinical ${ }_{1}^{3-5}$ and public health ${ }^{6}$ perspective.

Nevertheless, it is still far from being standard practice. Evidence-based decision aids are meant to facilitate the shift from paternalism to styles of practice that involve patients and their families. According to the last update of a Cochrane review on decision aids, ${ }^{7}$ only 45 of the more than 200 decision aids developed so far have met the inclusion criteria and were tested in randomized controlled trials (C. Bennett, oral communication, May 31,2007$).{ }^{8}$ The authors conclude that decision aids reduce decisional conflict and increase both knowledge and active involvement in care. No or only slight effects could be found on satisfaction with the decision, health effects, and the kind of option chosen. Observable effects suggest a tendency toward more-conservative choices, fewer operations, and less- 
intensive screening. Effects on decisional regret ${ }^{9}$ after treatment decisions have not been clarified because of the small number of trials.

Most decision aids are intended to be worked through by patients on their own. Even so, there is a need for testing transactional decision aids applied in the encounter between doctor and patient. ${ }^{10,11}$ Interactive, transactional decision aids underline the idea of sharing decisions between patient and doctor. Decision aids used within the consultation might also change physicians' behavior and help overcome barriers against implementing shared decision making. Such decision aids tend to have a different structure, relying more on structured communication and provision of options between patients and well-prepared physicians during consultation. ${ }^{12-15}$

The case for shared decision making is particularly strong with regard to cardiovascular disease (CVD) prevention. Here patients have to consider behavior change, for example, to give up smoking, to start exercise, or to take long-term medication, such as aspirin or drugs that lower blood pressure or cholesterol levels. Especially for the latter, there is a plethora of high-quality prospective studies with relevant end points available to inform patients' and physicians' decisions. ${ }^{16-20}$ Family doctors are not only expected to inform and involve their patients; in CVD prevention the physician's focus is also shifting from individual risk factors, such as hypertension or hyperlipidemia, to global risk as a guide for preventive action. ${ }^{21}$ Currently, neither individual CVD risk calculation ${ }^{15,22}$ nor engagement of patients in their own health care decisions, although regarded as effective, ${ }^{23}$ can be considered as standard care.

We developed a simple, evidence-based decision aid (ARRIBA-Herz) to help physicians achieve the double paradigm shift toward shared decision making and global CVD risk. The development process was based on recommendations of the CREDIBLE criteria published in the Cochrane review on decision aids. Central to ARRIBAHerz is a script of 6 steps that fits in with family practice consultation (Table 1). The concomitant materials, comprising a booklet for family doctors, a risk calculator, and an individual summary sheet for the patient, follow this structure to allow easy adoption in primary care practice (available in German and English at http://www.arriba-herz.de; see also the online-only Supplemental Appendix,

available at http://www.annfammed. org/cgi/content/full/6/3/218/DC1). Before the trial described in this report started, ARRIBA-Herz had undergone a 3-year phase I/II development process with more than 200 family doctors. ${ }^{24,25}$ In 2006, after our study began, the International Patient Decision Aid Standards Collaboration (IPDAS) published 11 criteria to judge the quality of decision aids. ${ }^{26}$ Most of these criteria have been fulfilled, however, patients had not yet participated in the development of ARRIBA-Herz. In a current phase IV study applying ARRIBA-Herz in routine care, opinions and suggestions of patients are extensively investigated. We describe the results of the phase III trial in family practice that evaluates the effectiveness of ARRIBA-Herz as judged by patients.

\section{METHODS}

\section{Design}

The trial was designed to best reflect current family practice. Because most German family doctors are organized into CME groups, in which participation is mandatory for public health insurance contracts, these groups constituted the units for recruitment, randomization, and provision of the educational intervention. Randomization to intervention or control group was stratified by the rural or urban location of member practices, which resulted in a 3-level cluster design in which the practice was nested within CME group and patients were nested within practice. Participating family doctors could not be blinded because of the intervention. Patients were informed that different kinds of risk communication and decision support would be assessed; they were unaware of their physicians' group allocation, however.

The study protocol was approved by the local research ethics committee.

\section{Participants}

All CME groups in the state of Hessen supervised by a large German quality management institute
Table 1. Decision Aid Steps: ARRIBA-Herz - The Script

\begin{tabular}{ll}
\hline Step & Components \\
\hline 1. Agree on task & $\begin{array}{r}\text { Calculate individual absolute risk for stroke and/or } \\
\text { myocardial infarction, involving patient in deci- } \\
\text { sion making } \\
\text { Address fears, expectations, preferences, ques- } \\
\text { tions of patients }\end{array}$ \\
$\begin{array}{l}\text { 2. Explore subjective risk } \\
\text { objective risk }\end{array}$ & $\begin{array}{l}\text { Assess individual risk factors (eg, age, blood pres- } \\
\text { with population with identical sex and age, pro- } \\
\text { vide probabilities in absolute numbers }\end{array}$ \\
$\begin{array}{l}\text { 4. Present preventive options } \\
\text { Include behavioral change and medication } \\
\text { Include nonaction }\end{array}$ \\
6. Agree on course of action
\end{tabular}


(AQUA) were screened for eligibility (Figure 1 displays a flowchart of participants). We excluded CME groups if several members had taken part in previous meetings on ARRIBA-Herz or if they routinely used other cardiovascular risk calculators. Thirty CME groups comprised 162 family doctors who were eligible and agreed to participate. Some small CME groups were merged to make up 9 to 13 participants in each CME group, resulting in $14 \mathrm{CME}$ groups with 162 physicians. One hundred twenty-seven family doctors attended the first of 2 educational sessions in either the intervention or the control arm. After the participating physicians had completed the educational sessions, we asked them to recruit up to 15 of their adult patients. Study nurses visited each practice to familiarize practice teams with study procedures and materials. To make sure that similar patients were included in both study arms, physicians were asked to approach all consecutive patients who had their cholesterol levels measured during a period of 4 weeks. We audited practices via telephone 3 times during the recruitment period to confirm consecutive recruitment. The only exclusion criterion on patient level was insufficient knowledge of German language. As a result, our sample included patients with and without clinical vascular disease.

Rolling recruitment of patients from each practice was spread evenly from May 2005 to March 2006. Six months after the index consultation, all participating patients were invited to a follow-up visit.

Ninety-one family doctors recruited at least 1 patient each. Our analysis is based on these family doctors and their study patients. Five hundred fifty patients were recruited by family doctors in the intervention arm, and 582 by family doctors in the control arm. Two hundred six patients were lost to follow-up, of which 82 were lost because their physician no longer participated in the study (Figure 1).
Figure 1. Study flowchart-CME groups, practices, and patients.

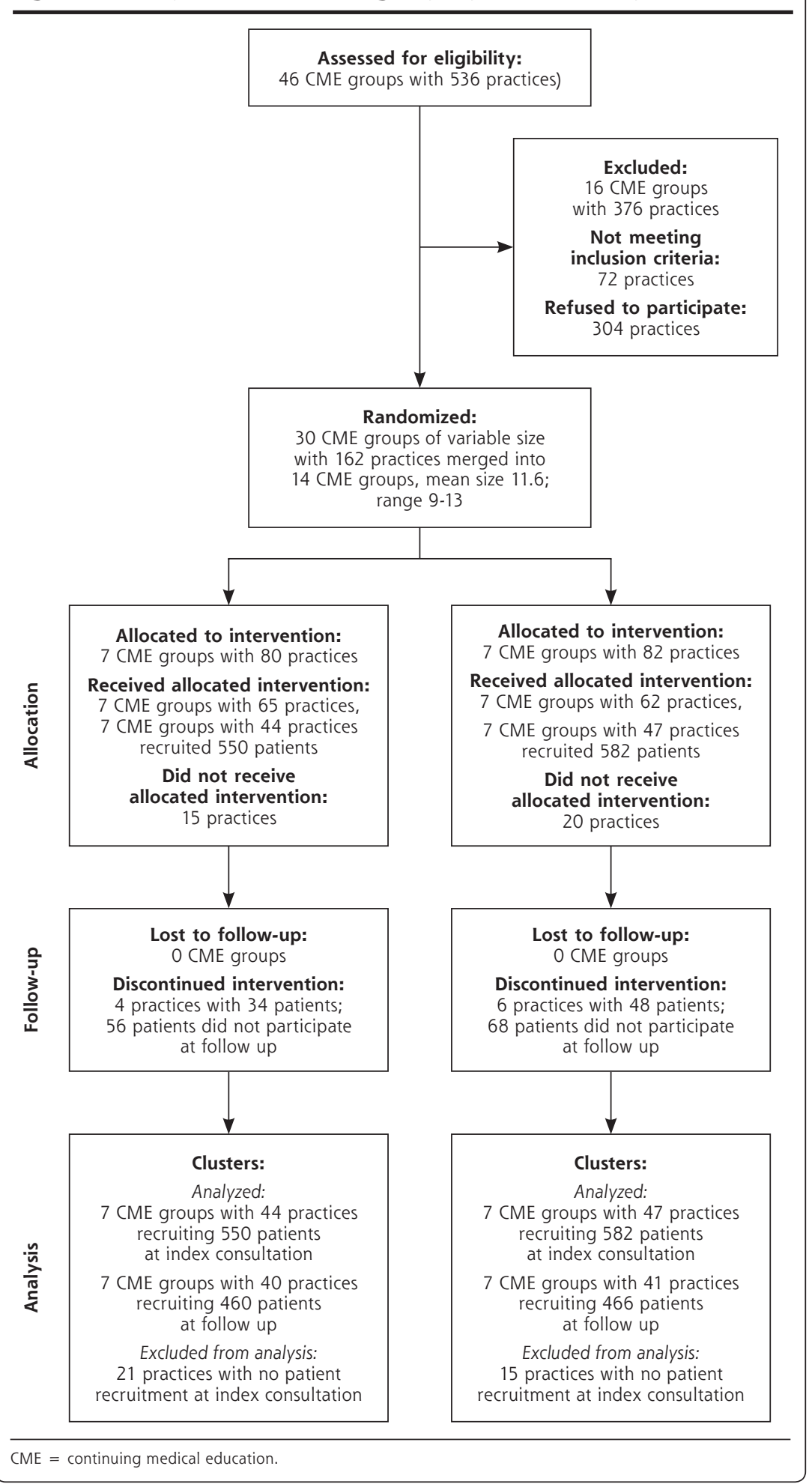




\section{Delivery of Intervention}

\section{Physicians}

The moderators of CME groups in the intervention arm, who worked as family doctors themselves, were invited to a training session at our Department of Family Practice to prepare them to moderate, together with members of our research team, the subsequent ARRIBA-Herz session in their respective groups. Participants in the intervention arm had to attend $2 \mathrm{CME}$ sessions lasting 2 hours each. Although we discussed the epidemiological background of global CVD risk calculation and ethics of shared decision making, we emphasized practical communication strategies and materials to be applied during consultation. Using the script-like decision aid was practiced through role playing. Participants received feedback from peers in their groups. To keep family doctors in the control arm motivated, we offered seminars on defined alternative topics that would not interfere with CVD prevention (placebo-CME). After completion of the trial, physicians in the control arm were offered meetings on ARRIBA-Herz and materials.

\section{Patients}

The counseling was structured according to the 6 steps (Table 1) also included in the decision aid. The patient's perspective on prevention of CVD (step 1, agree on task; step 2, talking about subjective risk) was addressed first, and patients were invited to a shared decision-making process. Physicians then calculated each patient's absolute risk for stroke and myocardial infarction on the basis of an adapted Framingham algorithm with the decision aid (Supplemental Appendix, decision aid, part 1). Individual prognosis was compared with age- and sex-adjusted population risk (Supplemental Appendix, decision aid, part 1, graph). For patients in secondary prevention, we assumed about $50 \%$ absolute risk for stroke or myocardial infarction in the next 10 years. This assumption was based on a secondary prevention trial calculating a relative risk reduction of preventive measures amounting $40 \%$ overall. ${ }^{27}$ Individual prognosis was displayed through marked smiley faces (smileys) (decision aid, part 2). The possible effects of single or multiple interventions were calculated by applying the specific relative risk reduction (decision aid, part 2) on the calculated and demonstrated absolute risk, which was visually supported by smileys being crossed out, ie, events prevented. Physicians were taught to calculate and show the effect of several preventive measures simultaneously.

\section{Measures}

Patient participation and satisfaction were measured by the Patient Participation Scale immediately after the index consultation. ${ }^{28-30}$ The Patient Participation Scale was also our primary outcome measure. For secondary measures of shared decision making, we included the shared decision making Q (SDM-Q) scale and an instrument on decisional regret. The former evaluates 9 stages of the decision-making process according to published theoretical frameworks., 4,31,32 After a pilot test, ${ }^{29}$ we decided to use a short form of the SDM-Q scale in which dichotomous items represent each predefined step. We analyzed every item and calculated sum scores of all items. Moreover, we asked for participation preferences in a 1 -item question. Finally, patients were asked 3 knowledge items relevant to CVD prevention. In our pilot study, we used a longer knowledge scale. Because of feasibility issues, we decided to apply only a short scale, calculating a sum score of right answers (with don't know and missing values counting as zero). We used the decisional regret scale ${ }^{9}$ for shared decision-making measurement at follow-up. Before we asked the question on decisional regret, we asked whether they remembered the decision 6 months ago. Only those who could remember the decision were asked to fill out the decisional regret scale.

Family doctors provided data on risk factors to calculate a CVD risk score for each patient at baseline and at follow-up. Because of its repeatedly proven high external validity, we used the Framingham Scoring system $^{33}$ calibrated for European populations. ${ }^{34}$ As a result, not only could we compare intervention and control patients in primary prevention with regard to their risk status, but we could also estimate a change of risk factors for all patients during study follow-up, because the focus was on relative change of global risk. We hypothesized that at 6 months' follow-up, the risk of patients in the intervention arm would not be worse than that of patients in the control arm. We also measured immediate preventive actions (prescribing drugs, plans to exercise) and sense of control by the theory of planned behavior as secondary outcome measures, which will be subject to subsequent analysis.

\section{Sample Size Calculation}

The sample size was calculated assuming an effect size of 0.3 as defined by Cohen, ${ }^{35}$ representing a small effect size of one-third of a standard deviation for the primary outcome measure, corresponding to 1 point on the Patient Participation Scale. Defining the patient as the unit of analysis, we estimated that a minimum number of 352 patients (176 per group) would be required to detect an effect of 0.3 with a power of $1-\beta=80$ using a 2 -sided 2 -sample $t$ test at a .05 significance level. We estimated an intracluster correlation coefficient (ICC) of 0.088 at practice level according 
to German studies on shared decision making ${ }^{30-32}$ in family practice, an average cluster size of 15 , and estimated a design effect of $\mathrm{D}=1+(15-1) \times 0.088=2.232$. Thus, to have adequate power, the sample size had to be increased to 786 patients (393 per group). ${ }^{36}$ Because we did not have estimates for ICC on CME group level and to compensate for dropouts and missing data at follow-up, we aimed for a conservative sample size of 1,100 patients (550 per group).

\section{Analysis}

We carried out coding and data entry in Microsoft Access (Microsoft Corp, Redmond, Washington). For binary/continuous outcome variables, we analyzed differences between groups by using random effect models in Stata, version SE 10.0 (StataCorp LP, College Station, Texas) and mixed models in SPSS, version 13.5, mixed models (Statistical Package for the Social Sciences, SPSS Inc, Chicago, Illinois) to allow for clustering by practice and CME group (practice nested within CME group), with the study arm as fixed effect. We added all relevant baseline characteristics at practice level (size, age, and sex of family physician, urban/rural) and patient level (CVD risk, diabetes, clinical vascular disease [yes/no], interaction of risk, diabetes, secondary prevention, age, sex, and education) as covariates to the models. Results of 2sided tests between study arms were regarded significant at $P<.05$.

We estimated ICC of practice and CME groups for binary outcomes by using the Stata procedure "xtmelogit" We used the model-based REML variance component estimates in SPSS for calculation of ICC of continuous variables.

High-density lipoprotein (HDL) cholesterol measurement is required for the Framingham risk formula; however, family physicians failed to measure HDL cholesterol in 108 patients. We imputed missing values for HDL cholesterol, and single missing values for age, total cholesterol level, and systolic blood pressure by using a maximum likelihood-based algorithm (EM algorithm).

\section{RESULTS}

\section{Baseline Comparisons}

\section{CME Groups and Family Doctors}

Baseline characteristics of practices are shown in Table 2. Because there were slight imbalances with regard to family doctors' age and practice size, we included these characteristics in all multivariate analyses, as described above.

\section{Patients}

At the patient level, the study arms were well balanced for sociodemographic characteristics, prevalence of individual risk factors, and clinical disease, as well as global risk and subjective health. The number of patients with diabetes was significantly higher among controls (Table 3), however. As a consequence, we included diabetes (yes/no) in addition to clinical vascular disease (secondary prevention yes/no) as covariates in our analysis (see above). Patients' participation preference in decision making also differed significantly in the 2 study arms, which might represent a selection bias in the intervention group or an intervention effect. Because participation preferences were evaluated in the patient questionnaire after the index consultation, this variable cannot necessarily be interpreted as being independent. We did not include it into our main analysis; however, the results of sensitivity analyses including participation preferences did not differ significantly from those without (data not shown).

\section{Effect of the Intervention}

Based on the study's main outcome, the Patient Participation Scale, subjects in the intervention arm were significantly more satisfied and participated more in the decision-making process. Patients in the intervention arm also reported more steps of shared decision making in their consultation (Table 4).

The global effect on decision-making as measured by our primary outcome is reflected in the individual steps of shared decision making that patients reported immediately after the index consultation (Table 5). All statements suggested more patient involvement in the intervention arm. Most items were significant at a
Table 2. Baseline Characteristics of Participating Family Doctors by Intervention $(n=44)$ and Control Group $(n=47)$

\begin{tabular}{lcccc}
\hline & $\begin{array}{c}\text { Intervention } \\
\text { Group } \\
\text { No. (\%) }\end{array}$ & $\begin{array}{c}\text { Control } \\
\text { Group } \\
\text { No. (\%) }\end{array}$ & $\chi^{2}$ & P Value \\
\hline GP age, years & & & 3.8 & .279 \\
$31-40$ & $2(4.5)$ & $1(2.1)$ & & \\
$41-50$ & $24(54.5)$ & $24(51.1)$ & & \\
$51-60$ & $17(38.6)$ & $16(34.0)$ & & \\
$>60$ & $1(2.3)$ & $6(12.8)$ & & \\
Male & $27(61.4)$ & $26(55.3)$ & 3.4 & .671 \\
Geographical location & $20(45.5)$ & $20(42.6)$ & 0.07 & .837 \\
(\% urban) & & & & \\
Practice size (practice & & & & \\
attendance per & & & & \\
3-month period) & 11.4 & \\
$\quad<500$ & $6(13.3)$ & $3(6.4)$ & & \\
500-1,000 & $19(40.4)$ & & \\
1,000-1,500 & $21(47.7)$ & $18(38.3)$ & & \\
$>1,500$ & $16(36.4)$ & $7(14.9)$ & & \\
\hline
\end{tabular}


$P=.001$ level. Some ICCs on the practice level were quite high, suggesting a strong effect of individual doctors on shared decision-making practice in both study arms. Knowledge did not improve through intervention.

After 6 months, patients who could remember the decision and had completed the decisional regret scale (385 interventions, 377 controls), reported less decisional regret in the intervention arm. CVD risk of all patients who participated in follow-up decreased relative to baseline in both groups. No difference was found between the 2 study arms after controlling for cluster structure and confounders, and there was no difference in the $95 \% \mathrm{CI}$ difference between groups (Table 4). Nineteen patients (3.5\%) of the intervention group and 22 patients $(3.7 \%)$ of the control group experienced a severe cardiovascular event during follow-up, a difference that was not significant.

\section{DISCUSSION}

We were able to show that a decision aid based on absolute CVD risk can be successfully disseminated in the setting of family practice CME groups.
Patients attending intervention practices were more involved and expressed higher satisfaction. Additionally, they showed less decisional regret after 6 months. Furthermore, shared decision making, contrary to what

\section{Table 3. Baseline Characteristics of Patients by Intervention} and Control Group.

\begin{tabular}{|c|c|c|c|c|}
\hline Variable & $\begin{array}{c}\text { Intervention } \\
\text { Group } \\
(n=550)\end{array}$ & $\begin{array}{l}\text { Control Group } \\
(n=582)\end{array}$ & $\chi^{2}$ (df) & $\begin{array}{c}P \\
\text { Value }\end{array}$ \\
\hline Mean age, years (SD) & $59.1(12.3)$ & $58.6(12.5)$ & 0.69 & .49 \\
\hline Male, No. (\%) & $231(42.0)$ & $265(45.5)$ & $1.4(1)$ & .26 \\
\hline $\begin{array}{l}\text { Nationality German, } \\
\text { No. (\%) }\end{array}$ & $528(96.0)$ & $566(97.3)$ & $0.83(1)$ & .46 \\
\hline Education, No. (\%) & & & $2.1(4)$ & .71 \\
\hline No or basic education & $284(51.6)$ & $320(54.9)$ & & \\
\hline Medium education & $169(30.7)$ & $168(28.9)$ & & \\
\hline Higher education & $91(16.6)$ & $91(15.6)$ & & \\
\hline Smokers, No. (\%) & $102(18.5)$ & $108(18.6)$ & $0.0(1)$ & 1.0 \\
\hline Diabetic, No. (\%) & $63(11.5)$ & $140(24.1)$ & $30.1(1)$ & $<.001$ \\
\hline $\begin{array}{l}\text { Previous cardiovascular } \\
\text { disease, No. (\%) }\end{array}$ & $101(18.4)$ & $130(22.3)$ & $2.7(1)$ & .10 \\
\hline $\begin{array}{l}\text { Mean cardiovascular risk } \\
\text { at baseline }{ }^{a}(S D)\end{array}$ & $10.7(9.5)$ & $10.1(9.2)$ & 098 (899) & .33 \\
\hline $\begin{array}{l}\text { Subjective health status, } \\
\text { No. (\%) }\end{array}$ & & & $5.2(4)$ & .27 \\
\hline Very good/good & $266(48.4)$ & $260(44.7)$ & & \\
\hline Satisfactory & $242(44.0)$ & $278(47.8)$ & & \\
\hline Very bad/bad & $36(6.5)$ & $40(6.9)$ & & \\
\hline $\begin{array}{l}\text { Preference of participation } \\
\text { in decision, No. (\%) }\end{array}$ & & & $13.4(4)$ & .009 \\
\hline Patient only & $6(1.1)$ & $11(1.9)$ & & \\
\hline Patient mainly & $14(2.5)$ & $16(2.7)$ & & \\
\hline Patient and doctor & $405(73.6)$ & $383(65.8)$ & & \\
\hline Doctor mainly & $99(18.0)$ & $114(19.6)$ & & \\
\hline Doctor only & $15(2.7)$ & $39(6.7)$ & & \\
\hline
\end{tabular}

a Mean cardiovascular risk in \% for 10 years at baseline, calculated by Framingham risk points, is displayed for patients in primary prevention only, including patients with diabetes.

Table 4. Outcome Variables by Intervention, All Clusters (14 CME Groups) Contributing to Every Analysis

\begin{tabular}{|c|c|c|c|c|c|c|}
\hline Variable & $\begin{array}{l}\text { Intervention } \\
\text { Group }^{\mathrm{a}}\end{array}$ & $\begin{array}{l}\text { Control } \\
\text { Group }\end{array}$ & $\begin{array}{c}\text { Estimated ICC } \\
\text { of CME Groupl } \\
\text { Practice }\end{array}$ & $\begin{array}{c}\text { Difference } \\
\text { Intervention - } \\
\text { Control }(95 \% \mathrm{CI})\end{array}$ & $\begin{array}{l}\text { Adjusted } \\
\text { F Statistic }\end{array}$ & $\begin{array}{c}P \\
\text { Value }^{a}\end{array}$ \\
\hline \multicolumn{7}{|l|}{$\begin{array}{l}\text { Evaluation after index } \\
\text { consultation }\end{array}$} \\
\hline $\begin{array}{l}\text { Patient participation and } \\
\text { satisfaction }^{b}\end{array}$ & $6.76(501)$ & $7.56(536)$ & $0.00 / 0.06$ & $-0.80(-1.23$ to -0.37$)$ & 13.55 & $<.001$ \\
\hline SDM steps reported & $9.48(407)$ & $7.49(442)$ & $0.00 / 0.07$ & 1.99 (1.27 to 2.71$)$ & 30.21 & $<.001$ \\
\hline Knowledge & $2.03(535)$ & $1.92(576)$ & $0.001 / 0.06$ & $0.11(-0.01$ to 0.24$)$ & 3.36 & .07 \\
\hline \multicolumn{7}{|l|}{ Follow-up examination } \\
\hline Mean change of CVD riskc & $-3.00(415)$ & $-3.33(407)$ & $0.006 / 0.02$ & $0.32(-0.30$ to 0.95$)$ & 1.07 & .31 \\
\hline Decisional regret & $14.69(372)$ & $18.08(372)$ & $0.00 / 0.02$ & $-3.39(-6.26$ to -0.53$)$ & 6.58 & .02 \\
\hline
\end{tabular}


is sometimes suspected, did not lead to a worsening of the global CVD risk status. A longer follow-up period than a one-half year in regard to CVD risk and decisional regret to confirm these effects in the long run seems warranted but was not feasible in our study. Yet, a longer intervention effect of a single consultation on these outcome parameters also seems unlikely.

The literature is abundant with failed attempts to change professional behavior. ${ }^{37,38}$ Several factors may have contributed to the intervention effect of ARRIBAHerz. A development process using several feedback loops between family doctors and an academic department prepared the ground for the definitive phase III study reported here. We designed a multifaceted implementation strategy ${ }^{39}$ consisting of educational seminars for existing CME groups, involvement of local opinion leaders (moderators of CME groups), printed materials, and aids for the consultation. We condensed insights from epidemiology, intervention studies, and risk communication in a single simple script to be used in family practice consultation. Successful implementation of innovative behavior among professionals, however, is often contingent upon external factors. In our case, pressure to contain prescribing costs and exaggerated claims of medication effect pose a dilemma to family doctors. ARRIBA-Herz seems to offer a practical solution to this dilemma.

Most decision aids on CVD prevention address one specific intervention only, such as antihypertensive drugs. ${ }^{40} \mathrm{~A}$ Canadian decision aid covering a broad range of options has only been tested in a small trial and appears to be long and very complex. ${ }^{41}$ Another comprehensive decision support tool developed in the Netherlands on CVD prevention that focuses on lifestyle changes was administered to patients by their family doctor. Like most decision aids developed

Table 5. Steps of Shared Decision-Making Process During Consultation as Reported by Patients Directly After Consultation

\begin{tabular}{|c|c|c|c|c|}
\hline Steps and Statements & $\begin{array}{l}\text { Intervention } \\
\text { Group } \\
\% \text { Agree (n) }\end{array}$ & $\begin{array}{l}\text { Control Group } \\
\% \text { Agree (n) }\end{array}$ & $P$ Value ${ }^{a}$ & $\begin{array}{c}\text { Estimated ICC } \\
\text { of CME Groupl } \\
\text { Practice }^{\mathrm{a}}\end{array}$ \\
\hline \multicolumn{5}{|l|}{ Step 1. Disclosure, that a decision needs to be made } \\
\hline My doctor told me that a treatment decision is necessary & $42.9(236 / 550)$ & $39.0(227 / 582)$ & .160 & $0.035 / 0.125$ \\
\hline \multicolumn{5}{|l|}{ Step 2. Formulation of equality of partners } \\
\hline My doctor asked me, if I want to participate in decision making & $64.2(353 / 550)$ & $46.1(268 / 582)$ & $<.001$ & $0.000 / 0.083$ \\
\hline \multicolumn{5}{|l|}{ Step 3. Equipoise statement ${ }^{b}$} \\
\hline $\begin{array}{l}\text { Due to my medical condition, treatment decision based on } \\
\text { physicians' recommendation is already clear }\end{array}$ & $53.8(296 / 550)$ & $58.4(340 / 582)$ & .867 & $0.000 / 0.000$ \\
\hline \multicolumn{5}{|l|}{ Step 4. Informing on the options' benefits and risks } \\
\hline My doctor has informed me about a variety of alternatives & $64.0(352 / 550)$ & $47.9(279 / 582)$ & $<.001$ & $0.000 / 0.203$ \\
\hline The possibility to choose no treatment was also discussed & $55.3(304 / 550)$ & $36.9(215 / 582)$ & $<.001$ & $0.000 / 0.076$ \\
\hline \multicolumn{5}{|l|}{$\begin{array}{l}\text { Step } 5 . \text { Investigation of patient's understanding and } \\
\text { expectations }\end{array}$} \\
\hline I have mentioned other possibilities that my doctor has not referred to & $14.4(79 / 550)$ & $8.9(52 / 582)$ & .075 & $0.000 / 0.089$ \\
\hline My doctor has asked me how I think about different treatment options & $62.9(346 / 550)$ & $37.6(219 / 582)$ & $<.001$ & $0.000 / 0.281$ \\
\hline \multicolumn{5}{|l|}{ Step 6. Identification of preferences (both) } \\
\hline I have communicated to my doctor which decision I do prefer & $55.5(305 / 550)$ & $34.7(202 / 582)$ & $<.001$ & $0.000 / 0.145$ \\
\hline My doctor has told me which decision he prefers & $68.9(379 / 550)$ & $57.6(335 / 582)$ & $<.001$ & $0.000 / 0.153$ \\
\hline \multicolumn{5}{|l|}{ Step 7. Negotiation } \\
\hline $\begin{array}{l}\text { In the selection of treatment method, my thoughts were taken into } \\
\text { account just as much as the considerations of my doctor }\end{array}$ & $77.1(424 / 550)$ & $61.3(357 / 582)$ & $<.001$ & $0.001 / 0.184$ \\
\hline $\begin{array}{l}\text { My doctor and I weighted up the different treatment options } \\
\text { thoroughly }\end{array}$ & $67.6(372 / 550)$ & $51.2(298 / 582)$ & $<.001$ & $0.000 / 0.113$ \\
\hline \multicolumn{5}{|l|}{ Step 8. Shared decision making } \\
\hline $\begin{array}{l}\text { My doctor enabled me to actively participate in decision making } \\
\text { about treatment }\end{array}$ & $79.1(435 / 550)$ & $64.3(374 / 582)$ & $<.001$ & $0.000 / 0.118$ \\
\hline My doctor and I selected a treatment together & $65.8(362 / 550)$ & $55.8(325 / 582)$ & .004 & $0.000 / 0.149$ \\
\hline \multicolumn{5}{|l|}{ Step 9. Arrangement of follow-up } \\
\hline My doctor and I reached an agreement as to how we will proceed & $78.9(434 / 550)$ & $70.4(410 / 582)$ & .006 & $0.013 / 0.196$ \\
\hline
\end{tabular}


so far, this tool was worked through by patients on their own. ${ }^{42}$ This decision aid did not change relevant subjective or clinical outcomes, the latter defined as adherence to guidelines on cardiovascular risk by patient and physician. Most decision aids included in the Cochrane review ${ }^{7}$ comprehensively inform patients and invite them to reflect upon different options on their own before consulting their doctor. These decision aids improved knowledge but often did not lead to higher satisfaction after consultation, perhaps because the doctors' behavior remained unchanged. Although the interactive decision aid tested in our study did not improve knowledge, it resulted in higher patient satisfaction and less decisional regret after 6 months. The small effect on knowledge might be because the decision aid was not designed as a consumer-oriented decision aid with comprehensive information material for patients, relying instead on the information of wellinformed family doctors during consultation. On the other hand, we might have underestimated the effect by using only a 3 -item sum scale.

The intervention induced a noticeable change in communication patterns as reported by patients (Tables 4 and 5). ARRIBA-Herz helped doctors and patients discuss individual concerns and pace information according to patients' needs. The responses to most statements referring to the theoretically defined steps of the shared decision-making process (Table 5) fit in with the study hypothesis.

For study outcomes we mainly defined soft variables, ie, patient participation, satisfaction, and decisional regret. Neither previous studies nor theoretical considerations suggest a substantial effect of decision aids on objective risk factors. We assessed CVD risk at 6 months' follow-up primarily to exclude a deterioration of risk factors caused by the intervention. We observed a reduction of 10-year CVD risk in both groups. We interpret this finding as an effect of regression to the mean. Confidence intervals reached from less than to more than zero, but they are sufficiently narrow so that a deterioration of CVD risk through the intervention seems unlikely. Larger studies are still indicated. We strongly believe, however, that the case for shared decision making predominantly rests on the subjective argument. More involvement and less decisional regret of patients can be regarded as important goals of health care per se, not only measurable utilities. ${ }^{2}$

Given the pragmatic study design with cluster randomization, blinding of family doctors was not possible. Although we required participating practices to recruit identical patients, family doctors in the control arm recruited more diabetic and slightly more high-risk patients in secondary prevention, and their colleagues in the intervention arm recruited more patients with higher preferences toward more participation in the decision-making process. The former effect might also be due to cluster, ie, practice characteristics, since 8 practices of the control arm as opposed to only 3 in the intervention arm recruited relatively high numbers of diabetic patients. Six of the control practices with high numbers of diabetic patients had implemented specific programs for diabetic patients. Higher numbers of patients with a preference for participation in the intervention arm, as already mentioned in the result section, might also represent an intervention effect, as the questionnaire was applied after the index consultation. Some physicians extended the recruitment period to 6 weeks, so that consecutive recruitment was presumably not always performed. Thus, a selection bias in the intervention group toward discussing prevention with low-risk patients and with patients with a stronger preference toward active participation cannot be excluded, as was also suggested by one of our preliminary studies. ${ }^{24}$ Because patient participation was the primary effectiveness measure, however, these imbalances do in our view not affect our main conclusions.

The setting of CME groups coordinated by the AQUA-Institute on behalf of the statutory ambulatory care organization allowed us to include family doctors who perhaps would not have taken part in a completely voluntary CME event. Furthermore, we excluded family doctors practicing certain features of the intervention already. We therefore assume that in our sample, the proportion of doctors adopting innovations at a later stage ${ }^{43}$ is larger than in the population. Thus, we might have underestimated intervention effects.

In conclusion, a decision aid for the prevention of CVD has been effectively disseminated through family practice CME groups. It is based on absolute risk and has a script-like structure specifically adapted for the consultation between patient and family physician. We believe, however, that both consumer-oriented and consultation-based decision aids are important, might be combined, and deserve further study.

To read or post commentaries in response to this article, see it online at http://www.annfammed.org/cgi/content/full/6/3/218.

Submitted December 4, 2007; submitted, revised, March 22, 2008: accepted March 26, 2008.

Key words: Shared decision-making; decision aids; cardiovascular diseases; risk; primary health care; continuing medical education; bioethics; chronic care decision support

Portions of the manuscript contents were presented at WONCA Conference, Florence, Italy, August 2006; International Shared Decision Mak- 
ing Conference, Freiburg, Germany, September 2007; DEGAM Conference, Berlin, Germany, September 2006.

Funding support: The study was funded by the German Federal Minis try of Education and Research, grant No. 01GK0401. Clinical trial registration number ISRCT71348772, at http://www.controlled-trials.com.

Acknowledgments: We acknowledge with thanks the assistance of our study coordinators Beate Czypionka, Ute Dietrich, and Ursula Siegmund. We would also like to thank all participating patients and family doctors. Grateful thanks also to Cornelia Kirst from the AQUA institute for contacting CME groups and to Uwe Popert for his contributions to the ARRIBA Decision Aid.

\section{References}

1. Brock D. The ideal of shared decision-making between physicians and patients. Kennedy Inst J Ethics. 1991;1:28-47.

2. Beauchamp T, Childress J. Principles of Biomedical Ethics. Oxford: Oxford University Press; 2001.

3. Charles C, Gafni A, Whelan T. Shared decision-making in the medical encounter: what does it mean? (Or it takes at least two to tango). Soc Sci Med. 1997;44(5):681-692

4. Edwards A, Elwyn G, eds. Evidence Based Patient Choice. Oxford: Oxford University Press; 2001.

5. Makoul G, Clayman ML. An integrative model of shared decision making in medical encounters. Patient Educ Couns. 2006;60(3): 301-312.

6. Kennedy ADM, Sculpher MJ, Coulter A, et al. Effects of decision aids for menorrhagia on treatment choices, health outcomes, and costs. JAMA. 2002;288(21):2701-2709.

7 O'Connor AM, Stacey D, Entwistle V, Llewellyn-Thomas H, Rovner D, Holmes-Rovner M. Decision aids for people facing health treatment or screening decisions. Cochrane Database Syst Rev. 2001;3: CD001431.

8. Bennett C, O'Connor AM, Stacey D, et al. Does the addition of 25 new trials to the Cochrane Review of patient decision aids change bottom line results? In: Härter M, Simon D, Loh A, eds. International Shared Decision Making Conference. Lengerich: Pabst Science Publishers; 2007:88

9. Brehaut JC, O' Connor AM, Wood TJ, et al. Validation of a decision regret scale. Med Decis Making. 2003;23(4):281-292.

10. O' Connor AM, Edwards A. The role of decision aids in promoting evidence-based patient choice. In: Edwards A, Elwyn G, eds. Evidence Based Patient Choice. Oxford: Oxford University Press; 2001: 220-242.

11. Williams S, Weinman J, Dale J. Doctor-patient communication and patient satisfaction: a review. Fam Pract. 1998;15(5):480-492.

12. Holmes-Rovner M, Valade D, Orlowski C, Draus C, Nabozny-Valerio $B$, Keiser S. Implementing shared decision making in routine practice: barriers and opportunities. Health Expect. 2000;3(3):182-191.

13. Edwards A, Elwyn G, Wood F, et al. Shared decision making and risk communication in practice. A qualitative study of GP's experiences. Br J Gen Pract. 2005;55(510):6-13.

14. Gigerenzer G, Edwards A. Simple tools for understanding risks: from innumeracy to insight. BMJ. 2003;327(7417):741-744.

15. Goldman RE, Parker DR, Eaton CB, et al. Patients' perceptions of cholesterol, cardiovascular disease risk, and risk communication strategies. Ann Fam Med. 2006;4(3):205-212.

16. Cholesterol Treatment Panel (CTT) Collaborators. Efficacy and safety of cholesterol-lowering treatment: prospective meta-analysis of data from 90056 participants in 14 randomized trials of statins. Lancet. 2005;366(9493):1267-1278.
17. Antithrombotic Trialists' Collaboration. Collaborative meta-analysis of randomised trials of antiplatelet therapy for prevention of death, myocardial infarction and stroke in high risk patients. BMJ. 2002;324(7329):71-86.

18. Psaty BM, Lumley T, Furberg CD, et al. Health outcomes associated with various antihypertensive therapies used as first-line agents: a network meta-analysis. JAMA. 2003;289(19):2534-2544.

19. Peto R, Lopez AC, Boreham J, Thun M, Heath C. Mortality from tobacco in developed countries: indirect estimation from national vital statistics. Lancet. 1992;339(8804):1268-1278.

20. Lowensteyn I, Coupal L, Zowall H, Grover SA. The cost-effectiveness of exercise training for the primary and secondary prevention of cardiovascular disease. J Cardiopulm Rehabil. 2000;20(3): 147-155.

21. Jackson R. Guidelines on preventing cardiovascular disease in clinical practice. BMJ. 2000;320(7236):659-661.

22. Jackson R, Lawes CMM, Bennett DA, Milne RJ, Rodgers A. Treatment with drugs to lower blood pressure and blood cholesterol based on an individual's absolute cardiovascular risk. Lancet. 2005;365(9457):434-441.

23. Coulter A, Ellins J. Effectiveness of strategies for informing, educating, and involving patients. BMJ. 2007;335(7609):24-27.

24. Donner-Banzhoff N, Keller H, Sadowski E, et al. Individualisierte |Risikoprognose für die Herz-Kreislauf-Prävention: ein Werkstattbericht. In: Kunz R, Ollenschläger G, Raspe H, Jonitz G, DonnerBanzhoff N, eds. Lehrbuch Evidenzbasierte Medizin. Köln: Deutscher Ärzteverlag; 2007:295-304.

25. Sadowski E, Eimer C, Keller H, et al. Evaluation komplexer Interventionen: Implementierung von ARRIBA Herz, einer Beratungsstrategie für die Herz-Kreislauf-Prävention. Z f Allg Med. 2005;81: 429-434.

26. Elwyn G, O'Connor AM, Stacey D, et al. Developing a quality criteria framework for patient decision aids: online international Delphi consensus process. BMJ. 2006;333(7565):417-423.

27. Poole-Wilson PA, Lubsen J, Kirwan BA, et al. A coronary disease trial investigating outcome with Nifedipine gastrointestinal therapeutic system investigators. Effect of long-acting nifedipine on mortality and cardiovascular morbidity in patients with stable angina requiring treatment (ACTION trial): randomised controlled trial. Lancet. 2004;364(9437):849-857.

28. Man-Son-Hing M, Laupacis A, O'Connor AM, et al. A patient decision aid regarding antithrombotic therapy for stroke prevention in atrial fibrillation. JAMA. 1999;282(8):737-743.

29. Krones T, Keller H, Sönnichsen AC, Sadowski EM, Baum E, Donner-Banzhoff N. Partizipative Entscheidungsfindung in der kardiovaskulären Risikoprävention: Ergebnisse der Pilotstudie von ARRIBA-Herz, einer konsultationsbezogenen Entscheidungshilfe für die allgemeinmedizinische Praxis [Shared decision making in cardiovascular prevention: results from the piloting of ARRIBA-Herz, a transactional decision aid for general practice]. Z Med Psychol. 2006;15(2):61-70.

30. Loh A, Leonhart R, Wills CE, Simon D, Härter M. The impact of patient participation on adherence and clinical outcome in primary care of depression. Patient Educ Couns. 2007;65(1):69-78.

31. Giersdorf N, Loh A, Bieber C, et al. Development and validation of assessment instruments for shared decision making. Bundesgesundheitsblatt Gesundheitsforschung Gesundheitsschutz. 2004;47(10):969-976.

32. Simon D, Schorr G, Wirtz M, et al. Development and first validation of the shared decision-making questionnaire (SDM-Q). Patient Educ Couns. 2006;63(3):319-327.

33. Sullivan LM, Massaro JM, D'Agostino RB. Presentation of multivariate data for clinical use: the Framingham Study risk score functions. Stat Med. 2004;23(10):1631-1660. 
34. Brindle P, Emberson J, Lampe F, et al. Predictive accuracy of the Framingham coronary risk score in British men: prospective cohort study. BMJ. 2003;327(7426):1267.

35. Cohen J. Statistical Power Analysis for the Behavioral Sciences. New York, NY: Academic Press; 1969.

36. Campbell MK, Elbourne DR, Altman DG. CONSORT statement: extension to cluster randomized trials. BMJ. 2004;328(7441): 702-708.

37. Oxman AD, Thomson MA, Davis DA, Haynes RB. No magic bullets: a systematic review of 102 trials of interventions to improve professional practice. CMAJ. 1995;153(10):1423-1431.

38. Davis $D$, Evans $M$, Jadad $A$, et al. The case for knowledge translation: shortening the journey from evidence to effect. BMJ. 2003;327(7405):33-35.

39. Campbell NC, Murray E, Darbyshire J, et al. Designing and evaluating complex interventions to improve health Care. BMJ. 2007;334(7591):455-459
40. Montgomery AA, Fahey T, Peters TJ. A factorial randomised controlled trial of decision analysis and an information video plus leaflet for newly diagnosed hypertensive patients. Br J Gen Pract. 2003;53(491):446-453.

41. Lalonde L, O'Connor AM, Duguay P, Brassard J, Drake E, Grover SA. Evaluation of a decision aid and a personal risk profile in community pharmacy for patients considering options to improve cardiovascular health: The OPTIONS pilot study. Int J Pharm Pract. 2006;14:51-62.

42. van Steenkiste B, van der Weijden T, Stoffers HEJH, Kester ADM, Timmermans DRM, Grol R. Improving cardiovascular risk management: a randomized, controlled trial on the effect of a decision support tool for patients and physicians. Eur I Cardiovasc Prev Rehabil. 2007;14(1):44-50.

43. Rogers EM. Diffusions of Innovations. New York, NY: The Free Press;1995

\section{CHANCE-OF-ADDRESS FORM FAMILY MEDICINE}

Please complete this form and mail to the following address or fax to Annals Circulation at 913-906-6080:

Annals of Family Medicine, Circulation Department, 11400 Tomahawk Creek Pkwy, Leawood, KS 66211-2680

Check if member of sponsoring organization:

$\square$ AAFP $\square$ ABFM $\square$ STFM $\square$ ADFM
$\square$ AFMRD $\square$ NAPCRG $\square$ CFPC

ID number from label on your journal cover

OLD Information (Please print.)

Name

Company (if applicable)

Address (Street plus Apt or Ste)

\begin{tabular}{ll}
\hline City & State \\
\hline Country & Postal Code (9-digit ZIP for US) \\
\hline Telephone & Fax \\
\hline E-Mail &
\end{tabular}

NEW Information (Please print.)

\begin{tabular}{ll}
\hline Name \\
\hline Company (if applicable) & \\
\hline Address (Street plus Apt or Ste) & \\
\hline City & Postal Code (9-digit ZIP for US) \\
\hline Country & Fax \\
\hline Telephone & \\
\hline E-Mail
\end{tabular}

